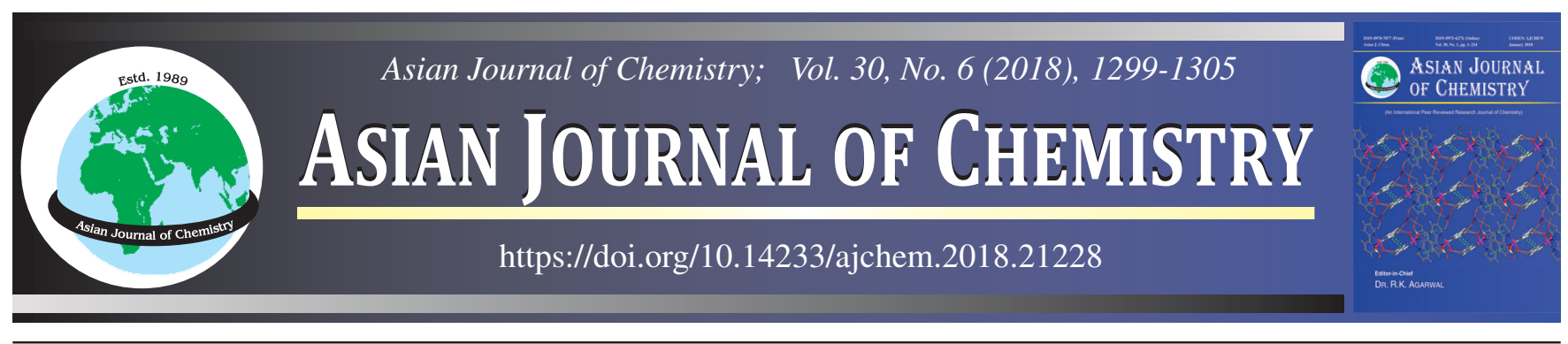

\title{
Triton X-100/ß-Cyclodextrin Cloud Point Extraction for Removal of Phenol Using Different of Sodium Salts as Inducing Phase Separation Agent
}

\author{
Saliza Asman* and Nur Azlie Abas
}

Department of Physics and Chemistry, Faculty of Applied Sciences and Technology, Universiti Tun Hussein Onn Malaysia, Pagoh Campus, 84600 Pagoh, Muar, Johor, Malaysia

*Corresponding author: E-mail: salizaa@uthm.edu.my

Received: 15 January 2018;

Accepted: 22 February 2018;

Published online: 30 April 2018;

AJC-18883

A simple and low-cost cloud point extraction (CPE) method was developed for the removal of phenol in water samples prior to its spectrophotometric detection. Two CPE methods i.e., CPE-(TX/ $\beta \mathrm{CD})-\mathrm{NaOH}$ and $\mathrm{CPE}-(\mathrm{TX} / \beta \mathrm{CD})-\mathrm{Na}_{2} \mathrm{CO}_{3}$ were developed based on Triton X-100/ $\beta$-cyclodextrin (TX-100/ $\beta$-CD) using electrolytes of sodium hydroxide and sodium carbonate, respectively as inducing phase separation agents. The effects of parameters; electrolytes, surfactant, $\beta$-cyclodextrin and analyte concentrations, temperature, incubation time and $\mathrm{pH}$ were evaluated in the context of extracting phenol from an aqueous media. Under optimized conditions, the $\mathrm{CPE}-(\mathrm{TX}-\beta \mathrm{CD})-$ $\mathrm{NaOH}$ was selected to extract phenol from real water samples due to its superior performance vis- $a-v i s \mathrm{CPE}-(\mathrm{TX}-\beta \mathrm{CD})-\mathrm{Na} \mathrm{CO}_{3}$. The calibration curve was linear in the range of 1.0 to $3.0 \mathrm{mg} \mathrm{L}^{-1}$ of phenol, with a regression coefficient of 0.9855 . The extraction efficiency in spiked and without spiked phenol in real water samples was in the range of 91.9-116.1\%. The results confirmed that the developed method can be applied satisfactorily to detect the presence of phenol in real water samples.

Keywords: Cloud point extraction, Triton X-100, $\beta$-Cyclodextrin, Sodium salts, Phenol.

ᄂ - - - - - - - - - - - - - - - - - - - - - - - - - - - -

\section{INTRODUCTION}

Phenol is a class of chemical compound that consists of a hydroxyl group (-OH). It is the main raw material and/or product of chemical and allied industries, such as petrochemicals, plastics, paint, steel industries, pesticides and oil refineries. Phenol is highly soluble in water and highly toxic with physically colourless and crystalline [1]. Various chronic toxic effects are pointed in humans such as anorexia, kidney and liver damage and mental disturbances [2].

Most phenols are easily found in the environment due to its widespread application in large-scale industries. Once the phenol compound present in untreated industrial effluents are released into the environment, they persist in the water for a week or more, adversely affecting life forms. They react with metal ions and other compounds present in the waste, resulting in the formation of more toxic complex compounds [3]. According to the recommendation of World Health Organization (WHO), the permissible concentration of phenolic content in potable water is $1 \mu \mathrm{g} \mathrm{L}^{-1}$, while the Environmental Protection Agency (EPA) call for lowered phenol content in wastewater to under $1 \mathrm{mg} \mathrm{L}^{-1}$ [4]. It is therefore necessary to remove phenol from water and wastewater prior to discharging it into a water stream in order to preserve public health and the environment.
Various removal and determination methods of trace phenolic content are continuously being developed, not only for monitoring the component, but also for controlling its presence in the environment. Methods such as chemical oxidation, adsorption, distillation, ozonation, ion exchange, membrane separation processes and reverse osmosis have been widely used to remove phenol from water [5-9]. Methods that can be used to determine the level of phenol in water samples include solid phase spectrophotometry, capillary zone electrophoresis, high performance liquid chromatography (HPLC), gas chromatography (GC) and pervaporation-flow injection [10-13]. However, some of these methods are complex, time-consuming and expensive. They are also difficult to use for analyzing complex matrix samples without pre-treatment.

A simple, fast, economical, greener, sensitive and selective analytical method is required to remove and determine the level of phenol analyte from water samples. Researchers are aware of the principles and advantages of cloud point extraction (CPE), as well as "green chemistry" as alternatives and environmentally friendly approaches. Cloud point extraction was firstly reported by Watanabe and Tanaka [14] and further developed by Quina and Hinze [15]. Up till now, it has been used for the removal, pre-concentration, separation and purification of a variety of substances, such as organic and inorganic 
pollutants in real-world samples, encompassing water, drug, cosmetic, food and biological samples.

It was confirmed that the CPE method, which is simple, low-cost, economical, highly efficient, biodegradable and benignly toxic is a suitable alternative to a more conventional extraction system. This method does not require any sophisticated instrument or high energy and reports higher extraction efficiency at lower costs. The aforementioned benefits are possible due to $\mathrm{CPE}$ being water-based and the high extraction efficiencies and pre-concentration factors can avoid the use of expensive and toxic solvents. The presence of surfactants can reduce extractant losses [16-18]. The CPE method is recognized by the phase behaviour of certain non-ionic surfactant in aqueous solutions, which can readily yield a surfactant-rich phase of small volume above the cloud-temperature $\left(\mathrm{T}_{\mathrm{C}}\right)$ $[19,20]$.

The influence of $\beta$-cyclodextrin on the aggregation of surfactants in aqueous solution is being intensely studied in colloid science. The development of CPE method, supported by $\beta$-cyclodextrin, could surpass the limitations of conventional CPE method due to its high extraction efficiency and pre-concentration factors. $\beta$-Cyclodextrin is cyclic oligosacc-harides and consist of seven $(\beta)$ units, which are joined together by $\alpha$ - $(1,4)$-glycosidic linkage bonds, forming toroidal-shape apolar cavities, lined with secondary hydroxyl groups at the mouth and primary hydroxyl groups at the opposite ends of the cavity. The internal diameter of the $\beta$ cyclodextrin is sufficient to permit the inclusion complexation with a variety of molecules. Therefore, $\beta$-cyclodextrin is able to form host-guest complexes with most surfactants' hydrophobic tails into cyclodextrin's cavities. Reported by Xu et al. [21] confirmed that the accumulation of $\beta$-cyclodextrin to the non-ionic surfac-tant solutions leads to growth of the aggregates instead of their dissociation. The solutions undergo micellar growth and micelle to vesicle transitions. Moreover, $\beta$-cyclodextrin is also important towards controlling the thicknesses of hydropho-bically modified polymers, e.g., ethyl(hydroxyl ethyl) cellulose and modified poly(ethylene glycol) in water by decoupling hydrophobic-hydrophobic intermolecular interactions [22,23]. Hence, the orientation of the $\beta$-cyclodextrin-surfactant com-plexes in the CPE is suitable towards the cooperative binding of the analyte recoveries.

The aim of this work is to investigate the CPE method in the context of removing the phenol content using TX-100 as a surfactant supported with $\beta$-cyclodextrin based on two types of sodium salts; sodium hydroxide and sodium carbonate, represented as cloud point extractionTriton X-100/ $\beta$-cyclodextrinsodium hydroxide; $\mathrm{CPE}-(\mathrm{TX} / \beta-\mathrm{CD})-\mathrm{NaOH}$ and cloud point extraction-Triton $\mathrm{X}-100 / \beta$-cyclodextrin-sodium carbonate; $\mathrm{CPE}-(\mathrm{TX} / \beta-\mathrm{CD})-\mathrm{Na}_{2} \mathrm{CO}_{3}$. The effects of the operating parameters, e.g. types of electrolytes, the concentration of electrolytes, the concentration of surfactant, the concentration of $\beta$-cyclodextrin, concentration of analyte, $\mathrm{pH}$, temperature and incubation time on the extraction of phenol were studied in detail. Further, the performance of CPE-(TX/ $\beta-\mathrm{CD})-\mathrm{NaOH}$ was selected and investigated for the removal of phenol content in real water samples.

\section{EXPERIMENTAL}

The commercial surfactant of Triton X-100, phenol and $\beta$-cyclodextrin ( $\beta$-CD) $(99 \%)$ were purchased from SigmaAldrich (Germany). Salts such as sodium chloride, potassium chloride and potassium iodide were procured from R\&M chemicals (Malaysia), while sodium hydroxide and sodium carbonate were purchased from Bendosen chemicals (Malaysia). Hydrochloric acid and ethyl alcohol were procured from $\mathrm{HmbG} \AA$ chemicals (Malaysia). These chemicals were of analytical reagent grade and were used as is without further purification. Fresh working standard solutions were made by diluting stock solution, which was kept stable during the day. Distilled water was used throughout the experiments.

All measurements of absorption spectra and absorbance were carried out using a model T60 UV-Vis Jenway spectrophotometer (model 6715, UK) with $1 \mathrm{~cm}$ glass cells. The $\mathrm{pH}$ values were measured using a metrohm digital $\mathrm{pH}$ meter (model 632, Switzerland) with a combined glass electrode. The phase separation of CPE process was accelerated using anMPW-350R centrifuge (Behsa, Iran). A Clifton thermostatic water bath (Memmert, Germany) was used to keep the temperature constant in $\mathrm{CPE}$ experiments.

Preparation of CPE-(TX- $\beta C D$ )-NaOH and CPE-(TX$\beta C D)-\mathrm{Na}_{2} \mathrm{CO}_{3}$ systems: For the CPE procedure, two kinds of aliquots were prepared and offered as cloud point extraction(Triton-X 100/ $\beta$-cyclodextrin)-sodium hydroxide method; CPE-(TX- $\beta C D)-\mathrm{NaOH}$ and cloud point extraction-(Triton-X $100 / \beta$-cyclodextrin)-sodium carbonate method; CPE-(TX$\beta C D)-\mathrm{Na}_{2} \mathrm{CO}_{3}$. In case of the CPE-(TX- $\left.\beta \mathrm{CD}\right)-\mathrm{NaOH}, 10 \mathrm{~mL}$ of aliquot was obtained by blending a mixture of $90 \%(\mathrm{w} / \mathrm{v})$ of TX-100 surfactant, $1 \mathrm{~mL}$ of phenol analyte $\left(15 \mathrm{mg} \mathrm{L}^{-1}\right)$, $1 \mathrm{~mL}$ of $\beta$-cyclodextrin supramolecular $\left(20 \mathrm{mg} \mathrm{L}^{-1}\right)$ and $20 \%$ $(w / v)$ of $\mathrm{NaOH}$ salt. CPE-(TX100- $\beta \mathrm{CD}$ ) $-\mathrm{Na}_{2} \mathrm{CO}_{3}$ was prepared under the above-mentioned condition using a $20.0 \%(\mathrm{w} / \mathrm{v})$ of $\mathrm{Na}_{2} \mathrm{CO}_{3}$ salt as a salt-induced separation. The $\mathrm{pH}$ of the solution $(\mathrm{pH}=9)$ was adjusted in a glass centrifuge tube prior to the extraction process. Then, the solution was placed in a thermostatic bath at $50{ }^{\circ} \mathrm{C}$ for $15 \mathrm{~min}$, then centrifuged at $4,000 \mathrm{rpm}$ for $20 \mathrm{~min}$. After the two phases were separated, the aqueous phase was removed using a syringe and the surfactant-rich phase (SRP) at the bottom of the solution was kept at room temperature for $10 \mathrm{~min}$ to obtain a viscous surfactant-rich phase. The volume of the surfactant-rich phase was then measured. The concentration of the surfactant-rich phase was determined using UV-vis spectrophotometer. All the data reported in this study are the average of three measurements.

Optimization of parameter studies of CPE-(TX- $\beta C D)$ $\mathrm{NaOH}$ and $\mathrm{CPE}-(\mathrm{TX}-\boldsymbol{\beta C D})-\mathrm{Na}_{2} \mathrm{CO}_{3}$ systems: The main variables affecting the extraction process were studied, such as the types of electrolytes, the concentration of selected electrolytes, the concentration of Triton X-100, the concentration of $\beta$-cyclodextrin and the concentration of phenol analyte, equilibration temperature, equilibration time and the $\mathrm{pH}$. The extraction efficiency of the phenol by CPE-TX- $\beta C D$ from the water samples was measured using followed formulae:

$$
\text { Extraction efficiency }(\%)=\frac{\mathrm{C}_{\mathrm{s}} \mathrm{V}_{\mathrm{s}}}{\mathrm{C}_{\mathrm{o}} \mathrm{V}_{\mathrm{o}}} \times 100
$$


where $\mathrm{C}_{\mathrm{s}}=$ the phenol concentration in the surfactant rich phase; $\mathrm{V}_{\mathrm{s}}=$ the volume of surfactant rich phase; $\mathrm{C}_{\mathrm{o}}=$ the phenol concentration in the sample-surfactant mixture; $\mathrm{V}_{\mathrm{o}}=$ the volume of sample-surfactant mixture.

Determination of phenol in real water samples by using CPE-(TX-BCD)-NaOH: Five real water samples were selected for this study. A tap water sample was collected from the laboratory and labelled as tap water. A seawater sample was collected at location $2^{\circ} 02^{\prime} 39.12^{\prime \prime} \mathrm{N} ; 102^{\circ} 34^{\prime} 8.04 " \mathrm{E}$ and labelled as Seawater. Three water samples were collected from three lakes at locations $1^{\circ} 52^{\prime} 5.16^{\prime \prime} \mathrm{N} ; 103^{\circ} 06^{\prime} 44.64 " \mathrm{E}$, labelled Lakes A, B and C. The water samples were filtered using a $0.45-\mathrm{lm}$ nylon membrane filter to remove suspended particulate matter, then stored at $4{ }^{\circ} \mathrm{C}$ in the dark. Then, $2 \mathrm{~mL}$ of filtered water sample was added into the aliquot of CPE-(TX- $\beta C D)-\mathrm{NaOH}$ solution as per the recommended procedure.

\section{RESULTS AND DISCUSSION}

Effect of type of electrolytes on CPE-(TX- $\beta C D)$ system: As shown in Fig. 1, the type of electrolytes impacts the extraction efficiency of phenol. The electrolyte's ability to enhance recoveries of phenol was demonstrated by $\mathrm{NaOH}$ and $\mathrm{Na}_{2} \mathrm{CO}_{3}$, which was superior to the performance of other salts. The effect of $\mathrm{NaOH}$ and $\mathrm{Na}_{2} \mathrm{CO}_{3}$ in the $\mathrm{CPE}$ systems reported the formation of two phases (rich-surfactant and rich-aqueous phases). Phenol extraction was reported to be $33.83 \%$ for CPE-(TX/ $\beta$ $\mathrm{CD})-\mathrm{NaOH}$ and $31.96 \%$ for CPE-(TX/ $\beta-\mathrm{CD})-\mathrm{Na}_{2} \mathrm{CO}_{3}$. However, $\mathrm{NaCl}, \mathrm{KCI}$ and $\mathrm{KI}$ were poorly formed in these CPE systems. Additional electrolytes to the surfactant micellar solution can increase or decrease its cloud point temperature (CPT) [24]. Furthermore, the ionic strength of the solution can alter the cloud point temperature and facilitate the separation of two phases by altering the density of the bulk aqueous phase [15]. The results showed that the electrolytes derived from mono and divalent ion pairs such as $2 \mathrm{Na}^{+} / \mathrm{CO}_{3}{ }^{2-}$ reporting higher extraction efficiency for phenol compared to the monovalent ions (e.g., $\mathrm{Na}^{+} / \mathrm{Cl}^{-}, \mathrm{K}^{+} / \mathrm{I}^{-}$and $\left.\mathrm{K}^{+} / \mathrm{Cl}^{-}\right)$[25]. Moreover, the salting out effect is more pronounced for divalent salt $\left(\mathrm{Na}_{2} \mathrm{CO}_{3}\right)$ compared to that of monovalent salt $(\mathrm{NaCl}, \mathrm{KI}$ and $\mathrm{KCl})$. The influence of salting-out electrolytes is due to the dehydration of the polyoxyethylene chain by cations and increasing water molecule self-association by anions [26]. Taking into account the electrolytes effect, the result confirmed that the ability of phenol extraction efficiency is improved due to the CPE-(TX/ $\beta-\mathrm{CD})-\mathrm{NaOH}$ system. This could be explained by the solvophobic concept, where the kosmotropic ions, such as $\mathrm{OH}^{-}$, $\mathrm{CO}^{-}$or $\mathrm{Na}^{+}$exhibit stronger interaction with water molecules than the water molecules itself, rendering it capable of breaking water-water hydrogen bonds. The poor extraction efficiency of phenol towards the CPE systems from monovalent salts such as $\mathrm{NaCl}, \mathrm{KI}$ and $\mathrm{KCl}$ are due to the chaotropic ions $\left(\mathrm{Cl}^{-}\right.$, $\mathrm{K}^{+}, \mathrm{I}^{-}$), which reported weaker interactions with water molecules than the water molecules itself, thus interfering little in hydrogen bonding of the surrounding water.In facts, within the Hofmeister series of cations, the ability of salting-out of $\mathrm{Na}^{+}$exceeds that of $\mathrm{K}^{+}$[27].

Taking the above factors into account, $\mathrm{NaOH}$ and $\mathrm{Na}_{2} \mathrm{CO}_{3}$ were chosen and the developed CPE systems were represented

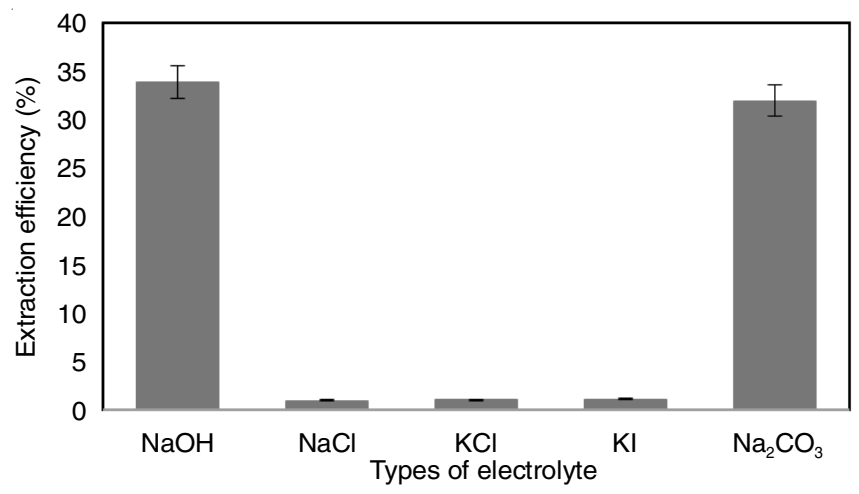

Fig. 1. Effect of types of salt. TX-100 surfactant concentration; $1.0 \%(\mathrm{w} / \mathrm{v})$; $\beta$-cyclodextrin $(\beta-\mathrm{CD})$ concentration $(\mathrm{v} / \mathrm{v}): 10 \mathrm{mg} \mathrm{L}^{-1}$; phenol concentration $(\mathrm{v} / \mathrm{v}): 10 \mathrm{mg} \mathrm{L}^{-1}$; equilibrium temperature $\left({ }^{\circ} \mathrm{C}\right) ; 50$; incubation time (min): 15 ; sample $\mathrm{pH}: 8.0$

as $\mathrm{CPE}-(\mathrm{TX} / \beta-\mathrm{CD})-\mathrm{NaOH}$ and $\mathrm{CPE}-(\mathrm{TX} / \beta-\mathrm{CD})-\mathrm{Na}_{2} \mathrm{CO}_{3}$ systems, respectively. Various concentrations ( 1.0 to $6.0 \%, \mathrm{w} / \mathrm{v}$ ) of both electrolytes were explored and applied to the phase equilibria (Fig. 2). It shows that the extraction efficiency of phenol rapidly increased from 1.0 to $2.0 \%$ ( $/ / \mathrm{v}$ ) of CPE-(TX/ $\beta-\mathrm{CD})$ $\mathrm{NaOH}$ and CPE-(TX/ $\beta-\mathrm{CD})-\mathrm{Na}_{2} \mathrm{CO}_{3}$ systems. Beyond $2.0 \%$ $(\mathrm{w} / \mathrm{v})$, higher electrolyte concentration decrease the extraction efficiency of phenol. This could be due to the salting-out effect inducing inter-attraction between micelles molecules itself, consequently leading to the precipitation of electrolytes and surfactant molecules [28]. The CPE-(TX/ $\beta-\mathrm{CD})-\mathrm{NaOH}$ has the ability to enhance recoveries of phenol compared to CPE(TX/ $\beta-\mathrm{CD})-\mathrm{Na}_{2} \mathrm{CO}_{3}$. Even though the $\mathrm{NaOH}$ and $\mathrm{Na}_{2} \mathrm{CO}_{3}$ contain the same cation $\left(\mathrm{Na}^{+}\right)$, the effect of the cation nature is usually smaller than that of the anion. As pointed out previously, the $\mathrm{OH}^{-}$(kosmotropic ion) is a stronger breaking agent compared with $\mathrm{CO}_{3}{ }_{3}$, which exhibit stronger interactions with water molecule than water molecules itself, thereby capable of rupturing hydrogen bonds between water-water hydrogen bonds and forming separate phases. Due to this, it is believed that the effect of $\mathrm{NaOH}$ was more pronounced than that of $\mathrm{Na}_{2} \mathrm{CO}_{3}$. In fact, within the Hofmeister series of anions, the effect of $\mathrm{OH}^{-}$ion was found to be maximized, meaning that it reported the highest viscosity of surfactant suspension among the concentration-viscosity characteristics of surfactant-rich phases. As a result of this, $1.0 \%(\mathrm{w} / \mathrm{v})$ of $\mathrm{NaOH}$ and $1.0 \%(\mathrm{w} / \mathrm{v})$ of $\mathrm{Na}_{2} \mathrm{CO}_{3}$ were, for CPE-(TX/ $\left.\beta-\mathrm{CD}\right)-\mathrm{NaOH}$ and $\mathrm{CPE}-(\mathrm{TX} / \beta$ -

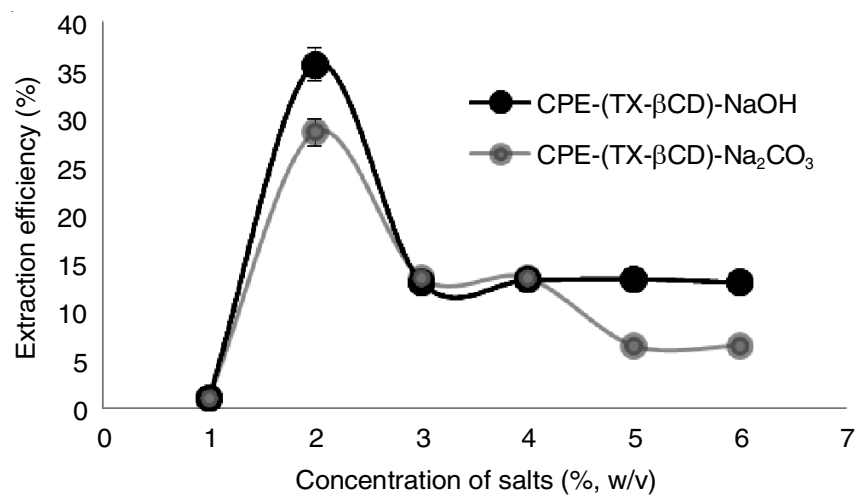

Fig. 2. Effect of salt concentration. TX-100 surfactant concentration; 1.0 $\%(\mathrm{w} / \mathrm{v}) ; \beta$-cyclodextrin $(\beta-\mathrm{CD})$ concentration $(\mathrm{v} / \mathrm{v}): 10 \mathrm{mg} \mathrm{L}^{-1}$; phenol concentration $(\mathrm{v} / \mathrm{v}): 10 \mathrm{mg} \mathrm{L}^{-1}$; equilibrium temperature $\left({ }^{\circ} \mathrm{C}\right)$ : 50; incubation time (min): 15; sample $\mathrm{pH}: 8.0$. 
CD)- $\mathrm{Na}_{2} \mathrm{CO}_{3}$ systems, respectively, the satisfied optimal electrolytes that were used for further analyses.

Effect of surfactant concentration on CPE-(TX- $\beta C D)$ $\mathrm{NaOH}$ and CPE-(TX- $\boldsymbol{\beta C D}$ )-Na $\mathrm{Na}_{2} \mathrm{CO}_{3}$ systems: The optimization of the influence of Triton-X 100 concentration on the sufficient extraction of phenol was conducted. There are some studies on the usage of Triton X-114 and PONPE-7.5 (cloud point temperature near room temperature) as surfactants to perform CPE for trace elements [29]. However, the whole system must be cooled in an ice bath to regain the surfactant-rich phase viscosity for easily decanting the bulk aqueous phase [30]. However, using Triton X-100, the tested solution could be easily separated into two phases and the bulk aqueous phase could be decanted after centrifugation, which precludes a cooling step due to the appropriate cloud point temperature of the surfactant. Under this circumstance, the influence of TX100 's concentration on the extraction of phenol was examined within the range from 1.0-13.0 \% (w/v) (Fig. 3). It was found that Triton X-100 could effectively extract phenol in concentrations of $9.0 \%(\mathrm{w} / \mathrm{v})$ and $7.0 \%(\mathrm{w} / \mathrm{v})$ for CPE-(TX- $\beta \mathrm{CD})$ $\mathrm{NaOH}(78.80 \%)$ and CPE-(TX- $\beta \mathrm{CD})-\mathrm{Na}_{2} \mathrm{CO}_{3}(68.99 \%)$, respectively. Phenol is a hydrophobic compound and the extraction of phenol with TX-100 solution could be mainly due to the hydrophobic interaction between phenol and hydrophobic micelles in the solution. When the concentration of TX-100 increased, the number of hydrophobic micelles in the solution increased as well, causing the responsive increase of the extraction ability of the TX-100 solution vis-a-vis phenol. Beyond the optimal concentrations of TX-100, the volume of surfactant-rich phase is too small to separate from the bulk solution, which complicates subsequent analysis, due to the reduced accuracy and precision. It is also expected that there are only a few molecules of the TX-100 surfactant that could quantitatively entrap sufficiently amount of phenol, which is indicative of insufficient TX-100 for recovery. Thus, a TX100 concentration of $7.0 \%(\mathrm{w} / \mathrm{v})$ and $9.0 \%(\mathrm{w} / \mathrm{v})$, respectively, for CPE-(TX- $\beta \mathrm{CD})-\mathrm{NaOH}$ and CPE-(TX- $\beta \mathrm{CD})-\mathrm{Na}_{2} \mathrm{CO}_{3}$ systems were selected for subsequent studies.

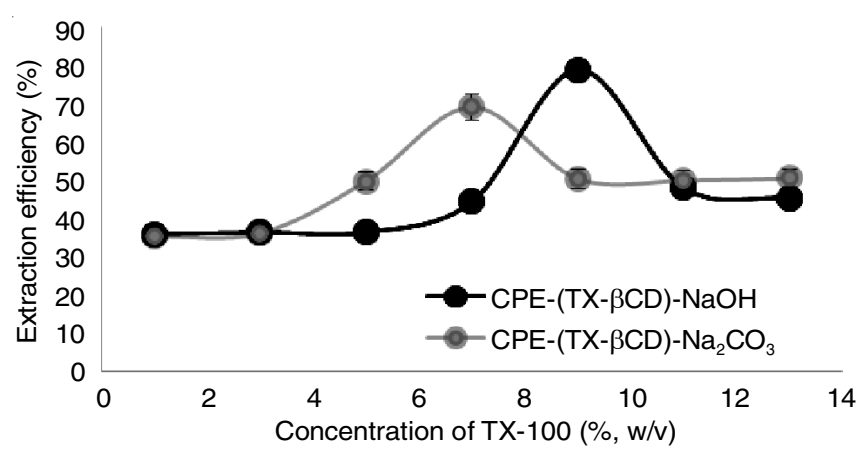

Fig. 3. Effect of TX-100 surfactant concentration. $\mathrm{NaOH}$ or $\mathrm{Na}_{2} \mathrm{CO}_{3}$ concentration: $1.0 \%(\mathrm{w} / \mathrm{v}) ; \beta$-cyclodextrin $(\beta-\mathrm{CD})$ concentration $(\mathrm{v} / \mathrm{v}): 10 \mathrm{mgL}^{-1}$; phenol concentration $(\mathrm{v} / \mathrm{v}): 10 \mathrm{mgL}^{-1}$; equilibrium temperature $\left({ }^{\circ} \mathrm{C}\right)$ : 50 ; incubation time (min): 15 ; sample $\mathrm{pH}: 8.0$

Effect of $\beta$-cyclodextrin ( $\beta$-CD) concentration on CPE(TX- $\beta C D)-\mathrm{NaOH}$ and $\mathrm{CPE}-(\mathrm{TX}-\beta \mathrm{CD})-\mathrm{Na}_{2} \mathrm{CO}_{3}$ systems: Due to better solubility in water and unique inclusion complexation of molecular recognition ability, $\beta$-cyclodextrin is presented as a modifier in these CPE. $\beta$-Cyclodextrin has been physically combined or chemically conjugated with TX-100 surfactant in CPE to enhance the extraction efficiency of phenol. Fig. 4 shows the influence of various concentration of $\beta$-cyclodextrin on the phase separation of aqueous TX-100 for the removal efficiency of phenol. The concentrations of $\beta$ cyclodextrin were investigated between $5.0-25.0 \mathrm{mg} \mathrm{L}^{-1}$. The result proved that the phase separation is dependent on $\beta$-cyclodextrin. It has the ability to enhance the extraction efficiency of phenol, which improves the CPE's system skill. The result confirmed that the extraction efficiency of phenol gradually increases with increasing $\beta$-cyclodextrin concentration. The extraction efficiency of phenol is highest at a concentration of $20 \mathrm{mg} \mathrm{L}^{-1} \beta$-cyclodextrin for both CPE systems. It was also confirmed that the inclusion complex possibly occurred between the $\beta$-cyclodextrin and the phenyl ring of the phenol, due to the hydrophobic species of phenol. In fact, the presence of $\beta$-cyclodextrin abruptly changes the turbidity, aggregate size and viscosity of the TX-100 solutions. $\beta$-Cyclodextrin provides a facile and effective approach for controlling the aggregation of non-ionic surfactant, which may in turn change the solution properties, leading to analyte recognition [31]. Beyond $20 \mathrm{mg} \mathrm{L}^{-1}$, the extraction efficiency of phenol decreases. It is speculated that if enough $\beta$-cyclodextrin is added to the micellar surfactant solution, all of the surfactant will eventually be complexed, resulting in the total breakdown of the micelles [32]. Thus, excess phenol is retained in the aqueous phase, resulting in a decrease of extraction efficiency of phenol in the CPE systems. It could also be attributed to the "dynamic equilibrium" concept [33]. Therefore, $20 \mathrm{mg} \mathrm{L}^{-1}$ of $\beta$-cyclodextrin concentration was selected for further experiment.

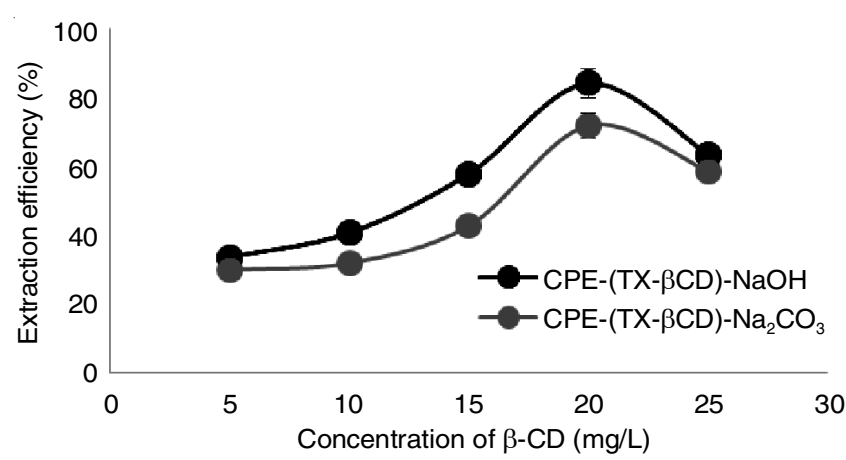

Fig. 4. Effect of $\beta$-cyclodextrin ( $\beta$-CD) concentration. TX-100 surfactant concentration: $70.0 \%(\mathrm{w} / \mathrm{v})$ and $90 \%(\mathrm{w} / \mathrm{v})$ for $1.0 \%(\mathrm{w} / \mathrm{v}) \mathrm{NaOH}$ or $1.0 \%$ (w/v) $\mathrm{Na}_{2} \mathrm{CO}_{3}$ concentration, respectively; phenol concentration (v/v): $10 \mathrm{mg} \mathrm{L}^{-1}$; equilibrium temperature $\left({ }^{\circ} \mathrm{C}\right)$ : 50 ; incubation time (min): 15 ; sample $\mathrm{pH}: 8.0$

Effect of phenol concentration on CPE-(TX- $\beta C D)$ $\mathrm{NaOH}$ and $\mathrm{CPE}-(\mathrm{TX}-\boldsymbol{\beta C D})-\mathrm{Na}_{2} \mathrm{CO}_{3}$ systems: Fig. 5 shows the influence of the initial concentration for the extraction efficiency of phenol on CPE-(TX/ $\beta-\mathrm{CD})-\mathrm{NaOH}$ and CPE-(TX/ $\beta-\mathrm{CD})-\mathrm{Na}_{2} \mathrm{CO}_{3}$ systems. The amount of TX-100 and $\beta$-cyclodextrin was kept constant, while the concentrations of phenol were varied between $5.0 \mathrm{mg} \mathrm{L}^{-1}$ and $25.0 \mathrm{mg} \mathrm{L}^{-1}$ in both CPE systems. The initial concentration induce a vital driving force between both the solute molecule on the surfactant and in the bulk phase in order to overcome the mass transfer resistance of phenol. The result confirmed that the extraction efficiency slightly increases from 5 to $15 \mathrm{mg} \mathrm{L}^{-1}$ for both CPE-(PEG/ 


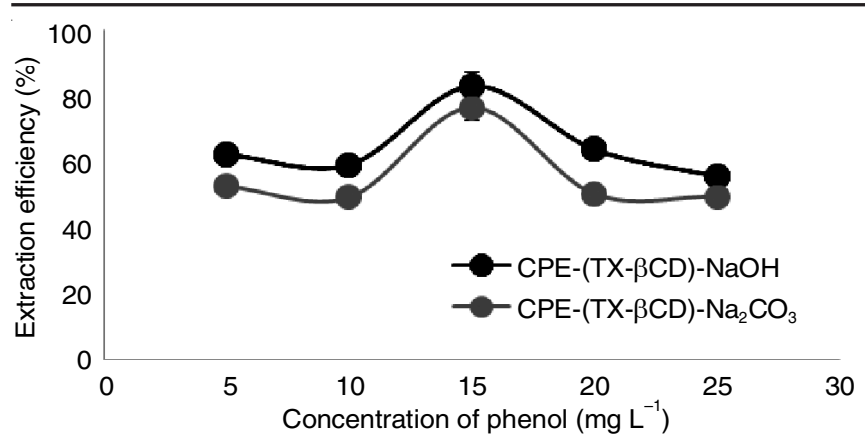

Fig. 5. Effect of phenol concentration. $\beta$-cyclodextrin $(\beta-\mathrm{CD})$ concentration (v/v): $20 \mathrm{mg} \mathrm{L}^{-1}$; TX-100 surfactant concentration: $70.0 \%(\mathrm{w} / \mathrm{v})$ and $90 \%(\mathrm{w} / \mathrm{v})$ for $1.0 \%(\mathrm{w} / \mathrm{v}) \mathrm{NaOH}$ or $1.0 \%(\mathrm{w} / \mathrm{v}) \mathrm{Na}_{2} \mathrm{CO}_{3}$ concentration, respectively; equilibrium temperature $\left({ }^{\circ} \mathrm{C}\right): 50$; incubation time ( $\mathrm{min}$ ): 15 ; sample $\mathrm{pH}: 8.0$

$\beta-\mathrm{CD})-\mathrm{NaOH}$ and $\mathrm{CPE}-(\mathrm{PEG} / \beta-\mathrm{CD})-\mathrm{Na}_{2} \mathrm{CO}_{3}$ systems. This is due to the large number of vacant surface micelles being available at the lowest/moderate concentration of solute. Hence, the solubilization of phenol molecules is easily embedded in the micellar core. Next, the extraction efficiency declined gradually with increasing concentration of phenol exceeding $15.0 \mathrm{mg} \mathrm{L}^{-1}$, which is probably due to the stability of the analyte-surfactant complex reduction. Further increase in the concentration of phenol leads to excess insolubilized phenol due to the insufficient amount of surfactant molecules. Consequently, excess phenol is retained in the aqueous phase, which accounted for the decreasing extraction efficiency of phenol in the CPE systems. The optimum phenol concentration at 15 $\mathrm{mg} \mathrm{L}^{-1}$ indicates that the phenol removal is higher for the CPE(PEG/ $\beta-\mathrm{CD})-\mathrm{NaOH}$ at $83.10 \%$, compared to the $\mathrm{CPE}-(\mathrm{PEG} /$ $\beta-\mathrm{CD})-\mathrm{Na}_{2} \mathrm{CO}_{3}$ at $76.57 \%$.

Effect of temperature and time incubation on CPE(TX- $\beta C D)-\mathrm{NaOH}$ and $\mathrm{CPE}-(\mathrm{TX}-\beta \mathrm{CD})-\mathrm{Na}_{2} \mathrm{CO}_{3}$ systems: The influence of the equilibration temperature on the extraction efficiency of phenol was investigated at 30,50 and $70{ }^{\circ} \mathrm{C}$, while the incubation time were studied within 5-25 min. Fig. 6 shows the temperature affecting to the extraction efficiency of phenol on the CPE-(TX/ $\beta-\mathrm{CD})-\mathrm{NaOH}$ and $\mathrm{CPE}-(\mathrm{TX} / \beta-\mathrm{CD})-$ $\mathrm{Na}_{2} \mathrm{CO}_{3}$ systems. The extraction efficiency was found to slowly increase from 30 to $50{ }^{\circ} \mathrm{C}$ due to the transfer of phenol into the complex of TX-100/ $\beta-C D$ rich phase. As a result of this, a temperature of $50{ }^{\circ} \mathrm{C}$ highlighting the extraction efficiency of phenol reported the highest value. The extraction efficiency of phenol was maximum at $50{ }^{\circ} \mathrm{C}$ for $\mathrm{CPE}-(\mathrm{TX} / \mathrm{\beta}-\mathrm{CD})-\mathrm{Na}_{2} \mathrm{CO}_{3}$ $(81.43 \%)$ and $\mathrm{CPE}-(\mathrm{TX} / \beta-\mathrm{CD})-\mathrm{NaOH}(87.09 \%)$. Later, phenol recovery slowly decreases as the temperature increases to 70 ${ }^{\circ} \mathrm{C}$ due to the decomposition of the complexes, caused by the migration of phenol from the cavity of the $\beta$-cyclodextrin. This is related to the surfactant phase volume, where the temperature disturbs the interactions in both phases (surfactantrich and aqueous phases) by decreasing the hydration of solutes. The CMC of non-ionic surfactant decreases when the temperature increases, thus decreases the extraction efficiency of phenol. In addition, the non-ionic surfactant performs rather more hydrophobic at a higher temperature due to an equilibrium shift, which favours dehydration of the ether oxygens, driving to an increase in the concentration of micelles [26]. Therefore, the solubilization capability of the micellar solution

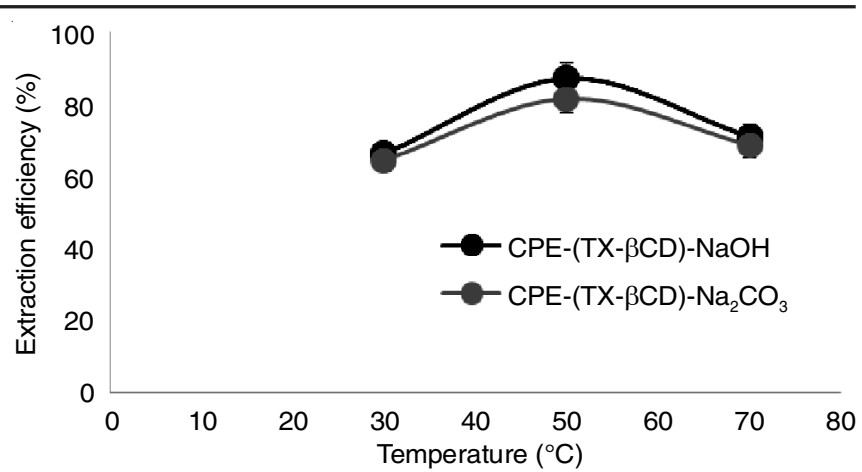

Fig. 6. Effect of equilibrium temperature. $\beta$-cyclodextrin $(\beta-C D)$ concentration $(\mathrm{v} / \mathrm{v}): 20 \mathrm{mg} \mathrm{L}^{-1}$; TX-100 surfactant concentration: $70.0 \%(\mathrm{w} / \mathrm{v})$ and $90 \%(\mathrm{w} / \mathrm{v})$ for $1.0 \%(\mathrm{w} / \mathrm{v}) \mathrm{NaOH}$ or $1.0 \%(\mathrm{w} / \mathrm{v})$ $\mathrm{Na}_{2} \mathrm{CO}_{3}$ concentration, respectively; phenol concentration: $15 \mathrm{mg}$ $\mathrm{L}^{-1}$; incubation time $(\mathrm{min})$ : 15 ; sample $\mathrm{pH}: 8.0$

increases alongside temperature, leading to an increase in phenol recovery. It should also be pointed out that the presence of electrolytes decreases the cloud point temperature and increases extraction efficiency $[15,34]$. Hence, an equilibration temperature of $50{ }^{\circ} \mathrm{C}$ was used as the best optimum temperature to affect the maximum extraction of phenol. The influence of the incubation time on CPE was investigated within 5-25 min by maintaining the temperature at $50^{\circ} \mathrm{C}$. Fig. 7 shows that an incubation time of $15 \mathrm{~min}$ is sufficient to complete the quantitative extraction of phenol for CPE-(TX/ $\beta-\mathrm{CD})-\mathrm{NaOH}(89.12 \%)$ and $\mathrm{CPE}-(\mathrm{TX} / \beta-\mathrm{CD})-\mathrm{Na}_{2} \mathrm{CO}_{3}(84.87 \%)$. When the incubation time increase to beyond $15 \mathrm{~min}$, the extraction efficiency of phenol decreases, which could be due to the instability of the phenol and surfactant complexes. Hence, an incubation time of $15 \mathrm{~min}$ at $50^{\circ} \mathrm{C}$ is optimal for the quantitative extraction of phenol.

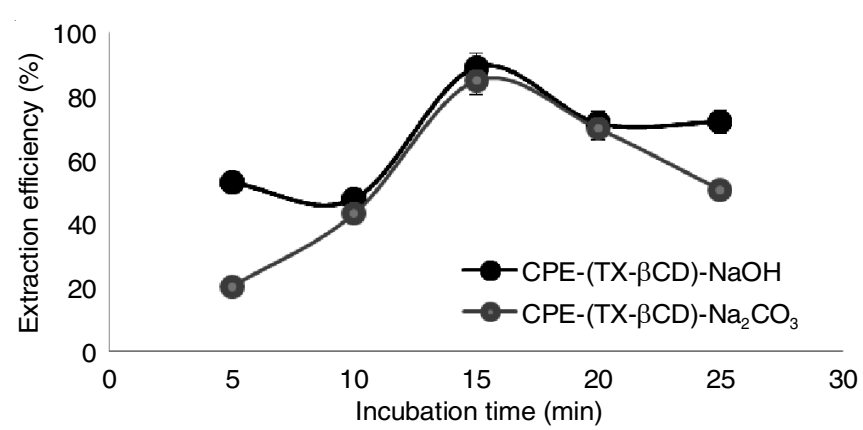

Fig. 7. Effect of incubation time. $\beta$-cyclodextrin $(\beta-\mathrm{CD})$ concentration: $20 \mathrm{mg} \mathrm{L}^{-1}$; TX-100 surfactant concentration: $70.0 \%(\mathrm{w} / \mathrm{v})$ and 90 $\%(\mathrm{w} / \mathrm{v})$ for $1.0 \%(\mathrm{w} / \mathrm{v}) \mathrm{NaOH}$ or $1.0 \%(\mathrm{w} / \mathrm{v}) \mathrm{Na}_{2} \mathrm{CO}_{3}$ concentration, respectively; phenol concentration: $15 \mathrm{mg} \mathrm{L}^{-1}$; equilibrium temperature: $50^{\circ} \mathrm{C}$; sample $\mathrm{pH}: 8.0$

Effect of pH study on CPE-(TX- $\beta \mathrm{CD})-\mathrm{NaOH}$ and CPE-(TX- $\boldsymbol{\beta C D}$ )- $\mathrm{Na}_{2} \mathrm{CO}_{3}$ systems: The influence of $\mathrm{pH}$ on the extraction efficiency of phenol was studied within $\mathrm{pH}$ 1-13. As shown in Fig. 8, the extraction efficiency of phenol gradually increased from $\mathrm{pH} 1$ to $\mathrm{pH} 7$. The highest extraction efficiency of phenol on CPE-(TX- $\beta \mathrm{CD}$ )-NaOH is $80.97 \%$ and CPE(TX- $\beta C D$ ) $-\mathrm{Na}_{2} \mathrm{CO}_{3}$ is $79.95 \%$ at $\mathrm{pH}$ 7. After $\mathrm{pH} 7$, the extraction efficiency starts to decrease as the $\mathrm{pH}$ becomes more basic. In an acidic medium the extraction efficiency is also low. The extraction efficiency of phenol is weak in an acidic medium 


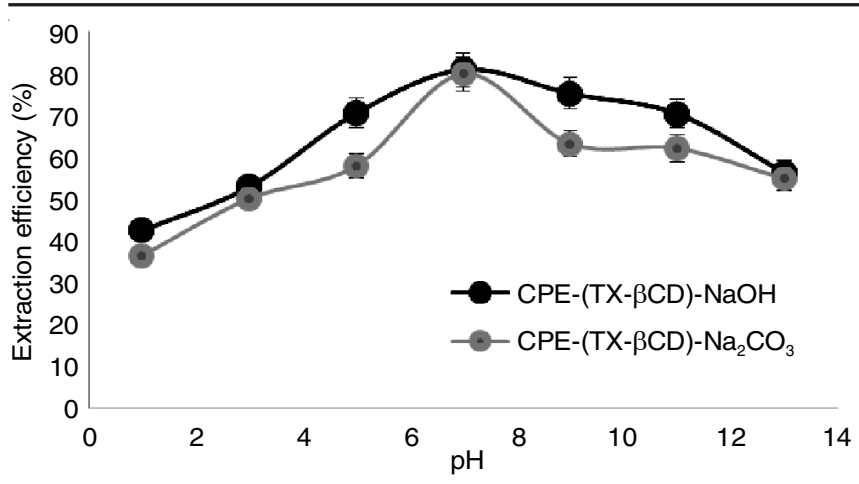

Fig. 8. Effect of pH. $\beta$-cyclodextrin ( $\beta$-CD) concentration: $20 \mathrm{mg} \mathrm{L}^{-1}$; TX100 surfactant concentration: $70.0 \%(\mathrm{w} / \mathrm{v})$ and $90 \%(\mathrm{w} / \mathrm{v})$ for $1.0 \%$ (w/v) $\mathrm{NaOH}$ or $1.0 \%$ (w/v) $\mathrm{Na}_{2} \mathrm{CO}_{3}$ concentration, respectively; phenol concentration: $15 \mathrm{mg} \mathrm{L}^{-1}$; equilibrium temperature: $50{ }^{\circ} \mathrm{C}$; incubation time (min): 15

because the phenol species are protonated and the ionic characteristics of phenol increase, leading to less phenol solubilization in the hydrophobic surfactant. Furthermore, the extraction efficiency is low in a basic medium due to the phenolate ions formation. The phenol is in its deprotonated form prominent to less interaction between surfactant and phenol. At neutral medium, the excellent interaction between surfactant and phenol can be occurred where the uncharged phenol prevails, driving to more phenol being successfully extracted in the surfactant-rich phase. The results confirmed that the neutral medium is the best for the extraction efficiency of phenol based on the TX-100/ $\beta-C D$ surfactant.

Determination of phenol in water samples based on optimized CPE-(TX-BCD)-NaOH: In order to test the reliability of the proposed methodology in the case of real samples, the feasibility of the developed CPE method was determined by spiking and not spiking phenol on the real water samples. A spiked phenol in real water samples is 0.4 and $4.0 \mathrm{mg} \mathrm{L}^{-1}$. The optimized CPE-(TX-100/ $\beta-\mathrm{CD}$ )-NaOH was used due to its excellent performance in extracting phenol analyte compared to the CPE-(TX-100/ $\beta-\mathrm{CD})-\mathrm{Na}_{2} \mathrm{CO}_{3}$ system. The calibration curve was constructed in the range of $1.0 \mathrm{mg} \mathrm{L}^{-1}$ to $3.0 \mathrm{mg} \mathrm{L}^{-1}$. The equation and regression coefficient are $\mathrm{A}=0.0695 \mathrm{x}-$ 0.067 and 0.9855 , respectively. The results are shown in Table- 1 and the extraction efficiency for phenol analytewas determined to be 91.9-116.1\%, confirming that the method can be considered reliable for the removal and determination of phenol in water samples.

\section{Conclusion}

In this work, a simple, fast, low cost and green method was developed for the removal of phenol from water samples using cloud point extraction (CPE) prior to its spectrophotometer detection.Two types of CPE methods have been developed; CPE-(TX/ $\beta-\mathrm{CD})-\mathrm{NaOH}$ and $\mathrm{CPE}-(\mathrm{TX} / \beta-\mathrm{CD})-\mathrm{Na}_{2} \mathrm{CO}_{3}$.Under optimized medium, the CPE-(TX/ $\beta-\mathrm{CD})-\mathrm{NaOH}$ was selected to remove the phenol in water samples, due to its superior extractability compared to the CPE-(TX/ $\beta-\mathrm{CD})-\mathrm{Na}_{2} \mathrm{CO}_{3}$. The experimental result clearly indicated the applicability of the $\mathrm{CPE}-(\mathrm{TX} / \beta-\mathrm{CD})-\mathrm{NaOH}$ system for removal of phenol in water samples. The method is non-toxic and does not require sophisticated instruments.

\begin{tabular}{|c|c|c|c|}
\hline \multicolumn{4}{|c|}{$\begin{array}{c}\text { TABLE-1 } \\
\text { EXTRACTION EFFICIENCY OF PHENOL } \\
\text { WITH AND WITHOUT SPIKED WATER SAMPLES }\end{array}$} \\
\hline $\begin{array}{c}\text { Water } \\
\text { samples }\end{array}$ & $\begin{array}{c}\text { Concentration } \\
\text { of spiked phenol } \\
\left(\mathrm{mg} \mathrm{L}^{-1}\right)\end{array}$ & $\begin{array}{c}\text { Phenol found } \\
\text { in real water } \\
\text { samples }\left(\mathrm{mg} \mathrm{L}^{-1}\right) \\
\end{array}$ & $\begin{array}{c}\text { Extraction } \\
\text { efficiency }(\% \\
\text { mean, } \mathrm{n}=3)\end{array}$ \\
\hline \multirow{3}{*}{ Tap water } & 0.0 & 0.3 & - \\
\hline & 0.4 & 0.5 & 100.7 \\
\hline & 4.0 & 4.1 & 93.9 \\
\hline \multirow{3}{*}{ Lake 1} & 0.0 & 0.3 & - \\
\hline & 0.4 & 0.8 & 98.3 \\
\hline & 4.0 & 4.2 & 102.5 \\
\hline \multirow{3}{*}{ Lake 2} & 0 & 0.4 & - \\
\hline & 0.4 & 0.7 & 96.7 \\
\hline & 4.0 & 4.1 & 101.2 \\
\hline \multirow{3}{*}{ Lake 3} & 0.0 & 0.5 & - \\
\hline & 0.4 & 0.6 & 102.9 \\
\hline & 4.0 & 4.2 & 91.9 \\
\hline \multirow{3}{*}{ Seawater } & 0 & 0.2 & - \\
\hline & 0.4 & 0.4 & 116.1 \\
\hline & 4.0 & 4.4 & 99.5 \\
\hline
\end{tabular}

\section{ACKNOWLEDGEMENTS}

The authors gratefully acknowledge to Universiti Tun Hussein Onn Malaysia (UTHM) for the Short Term Grant (STG) (U651-2017) as financial research support.

\section{REFERENCES}

1. V.C. Srivastava, M.M. Swamy, I.D. Mall, B. Prasad and I.M. Mishra, Colloids Surf. A, 272, 89 (2006);

https://doi.org/10.1016/j.colsurfa.2005.07.016.

2. S. Kumar, D. Arya, A. Malhotra, S. Kumar and B. Kumar, J. Environ. Chem. Eng., 1, 865 (2013);

https://doi.org/10.1016/j.jece.2013.07.027.

3. D.J. Swift, J. Fish Biol., 13, 7 (1978);

https://doi.org/10.1111/j.1095-8649.1978.tb03408.x.

4. $\quad$ N.N. Dutta, S. Borthakur and R. Baruah, Water Environ. Res., 70, 4 (1998); https://doi.org/10.2175/106143098X126838.

5. M.A. Al-Obaidi, C. Kara-Zaïtri and I.M. Mujtaba, J. Water Process Eng., 18, 20 (2017);

https://doi.org/10.1016/j.jwpe.2017.05.005.

6. K. Chen, S. Hao, H. Lyu, G. Luo, S. Zhang and J. Chen, Sep. Purif. Technol., 172, 100 (2017);

https://doi.org/10.1016/j.seppur.2016.08.004.

7. N. Othman, N.F.M. Noah, L.Y. Shu, Z.-Y. Ooi, N. Jusoh, M. Idroas and M. Goto, Chin. J. Chem. Eng., 25, 45 (2017);

https://doi.org/10.1016/j.cjche.2016.06.002.

8. L.G.C. Villegas, N. Mashhadi, M. Chen, D. Mukherjee, K.E. Taylor and N. Biswas, Curr. Pollut. Reports, 2, 157 (2016); https://doi.org/10.1007/s40726-016-0035-3.

9. H.B. Senturk, D. Ozdes, A. Gundogdu, C. Duran and M. Soylak, J. Hazard. Mater, 172, 353 (2009); https://doi.org/10.1016/j.jhazmat.2009.07.019.

10. M. Saraji and M. Bakhshi, J. Chromatogr. A, 1098, 30 (2005); https://doi.org/10.1016/j.chroma.2005.08.063.

11. I. Nukatsuka, S. Nakamura, K. Watanabe and K. Ohzeki, Anal. Sci., 16, 269 (2000); https://doi.org/10.2116/analsci.16.269.

12. S.Y. Sheikheldin, T.J. Cardwell, R.W. Cattrall, M.D. Luque de Castro and S.D. Kolev, Anal. Chim. Acta, 419, 9 (2000); https://doi.org/10.1016/S0003-2670(00)00991-0.

13. M.I. Turnes, M.C. Mejuto and R. Cela, J. Chromatogr. A, 733, 395 (1996); https://doi.org/10.1016/0021-9673(95)00800-4.

14. H. Watanabe and H. Tanaka, Talanta, 25, 585 (1978); https://doi.org/10.1016/0039-9140(78)80151-9.

15. F.H. Quina and W.L. Hinze, Ind. Eng. Chem. Res., 38, 4150 (1999); https://doi.org/10.1021/ie980389n. 
16. A. Favre-Réguillon, M. Draye, G. Lebuzit, S. Thomas, J. Foos, G. Cote and A. Guy, Talanta, 63, 803 (2004); https://doi.org/10.1016/j.talanta.2003.12.033.

17. C.C. Nascentes and M.A.Z. Arruda, Talanta, 61, 759 (2003); https://doi.org/10.1016/S0039-9140(03)00367-9.

18. D. Sicilia, S. Rubio, D. Pérez-Bendito, N. Maniasso and E.A.G. Zagatto, Anal. Chim. Acta, 392, 29 (1999); https://doi.org/10.1016/S0003-2670(99)00054-9.

19. M.F. Nazar, S.S. Shah, J. Eastoe, A.M. Khan and A. Shah, J. Colloid Interface Sci., 363, 490 (2011); https://doi.org/10.1016/i.jcis.2011.07.070.

20. C.D. Stalikas, Trends Analyt. Chem., 21, 343 (2002); https://doi.org/10.1016/S0165-9936(02)00502-2.

21. H.-N. Xu, S.-F. Ma and W. Chen, Soft Matter, 8, 3856 (2012); https://doi.org/10.1039/C2SM07371D.

22. A.J.M. Valente and O. Söderman, Adv. Colloid Interface Sci., 205, 156 (2014); https://doi.org/10.1016/j.cis.2013.08.001.

23. L. Karlson, K. Thuresson and B. Lindman, Carbohydr. Polym., 50, 219 (2002); https://doi.org/10.1016/S0144-8617(02)00036-X.

24. T. Tang, K. Qian, T. Shi, F. Wang, J. Li and Y. Cao, Anal. Chim. Acta, 680, 26 (2010); https://doi.org/10.1016/j.aca.2010.09.034.

25. A. Santalad, R. Burakham, S. Srijaranai, S. Srijaranai and R.L. Deming, J. Chromatogr. Sci., 50, 523 (2012); https://doi.org/10.1093/chromsci/bms043.
26. M.K. Purkait, S.D. Gupta and S. De, J. Hazard. Mater, 137, 827 (2006); https://doi.org/10.1016/j.jhazmat.2006.03.003.

27. N.N.M. Zain, M. Raoov, N.K. Abu Bakar and S. Mohamad, J. Inclusion Phenom. Mol. Recognit. Chem., 84, 137 (2016); https://doi.org/10.1007/s10847-015-0591-y.

28. H. Akbas and C. Batigöc, Fluid Phase Equilib., 279, 115 (2009); https://doi.org/10.1016/j.fluid.2009.02.014.

29. L.M. Coelho and M.A.Z. Arruda, Spectrochim. Acta B: Atom. Spectrosc., 60,743 (2005); https://doi.org/10.1016/j.sab.2005.02.016.

30. E.K. Paleologos, D.L. Giokas and M.I. Karayannis, Trends Analyt. Chem., 24, 426 (2005); https://doi.org/10.1016/j.trac.2005.01.013.

31. X. Zhu, X. Zhu, Y. Hu, S. Yu and B. Wang, Anal. Lett., 39, 1853 (2006); https://doi.org/10.1080/00032710600721522.

32. H.-N. Xu, S.-F. Ma and W. Chen, Soft Matter, 8, 3856 (2012); https://doi.org/10.1039/c2sm07371d.

33. D.J. Jobe, R.E. Verrall, E. Junquera and E. Aicart, J. Phys. Chem., 97, 1243 (1993); https://doi.org/10.1021/j100108a022

34. M. Singh, R. Sharma and U.C. Banerjee, Biotechnol. Adv., 20, 341 (2002); https://doi.org/10.1016/S0734-9750(02)00020-4. 